\title{
TRANSEXUALIDADE E DIFERENÇA SEXUAL: O QUE A CLÍNICA NOS ENSINA
}

\section{Transsexuality and Sexual Difference: What the Clinic Teaches Us}

\section{Transexualidad y Diferencia Sexual: ¿Qué nos Enseña la Clínica?}

\section{Transsexualité et Différence Sexuelle : Ce que la Clinique nous Apprend}

\author{
10.5020/23590777.rs.v20iEsp2.e8897
}

\section{Doris Luz Rinaldi 9}

Professora do Instituto de Psicologia da Universidade do Estado do Rio de Janeiro. Membro do Colegiado de Docentes do Programa de Pós-graduação em Psicanálise do IP/UERJ. Psicanalista, Membro de Intersecção Psicanalítica do Brasil.

\section{Mayara Yamauti Possari 9}

Psicóloga, Psicanalista e Acompanhante Terapêutica da Equipe Dom Quixote. Pós-graduação Lato Senso em Psicologia Clínica pela PUC-SP, Residência Multiprofissional em Saúde Mental pela UERJ e Mestrado em Psicanálise pela UERJ.

\section{Resumo}

Este trabalho aborda a questão transexual levando em conta uma dupla dimensão. Por um lado, considerando-a um fenômeno social que vem tomando proporções midiáticas cada vez maiores; por outro, com especial atenção ao sujeito em sua singularidade, a partir do pensamento clínico próprio à teoria psicanalítica. Para isso, pretende-se abordar a construção do diagnóstico transexual e seus desdobramentos, assim como atravessar o tema da diferença sexual a partir da psicanálise, situando seu campo teórico relativo ao inconsciente, com seus conceitos entrelaçados, que se distancia da abordagem biológica e das questões de gênero. Por fim, fragmentos de casos serão apresentados para desenvolver a discussão a partir do um a um.

Palavras-chave: transexualidade; diferença sexual; psicanálise.

\section{Abstract}

This work addresses the transsexual issue taking into account a double dimension. On one hand, considering it a social phenomenon that has been taking on ever greater media proportions; on the other, with special attention to the subject in its uniqueness, from the clinical thought proper to psychoanalytic theory. For this, it is intended to approach the construction of the transsexual diagnosis and its consequences, as well as to cross the theme of sexual difference from psychoanalysis, placing its theoretical field relative to the unconscious, with its intertwined concepts, which distances itself from the biological approach and gender issues. Finally, fragments of cases will be presented to develop the discussion from one to one.

Keywords: transsexuality; sexual difference; psychoanalysis.

\section{Resumen}

Este trabajo enfoca la cuestión transexual llevando en cuenta una dimensión doble. Por un lado, considerándola un fenómeno social que viene tomando proporciones mediáticas cada vez mayores; por otro, con especial atención al sujeto en su singularidad, a partir del pensamiento clínico propio de la teoría psicoanalítica. Para esto, se pretende enfocar la construcción del diagnóstico transexual a partir del psicoanálisis, ubicando su campo teórico relativo al inconsciente, con sus conceptos entrelazados, que se distancia del enfoque biológico y de las cuestiones de género. Por fin, serán presentados fragmentos de casos para desarrollar la discusión a partir del uno a uno. 
Palabras clave: transexualidad; diferencia sexual; psicoanálisis.

\section{Résumé}

Ce travail aborde la question transsexuelle en considérant une double dimension. D'une part, on la considère un phénomène social qui prend des proportions de plus en plus médiatiques ; de l'autre, on la prend avec une attention particulière au sujet dans sa spécificité, à partir de la pensée clinique propre à la théorie psychanalytique. Pour cela, on a l'intention d'aborder la construction du diagnostic transsexuel et ses conséquences. On va, aussi, traverser le thème de la différence sexuelle point de vue de la psychanalyse, dans son champ théorique relatif à l'inconscient, avec ses concepts entrelacés, qui s'éloignent de l'approche biologique et des questions de genre. Enfin, des fragments de cas seront présentés pour développer la discussion de un à un.

Mots-clés : transsexualité ; différence sexuelle ; psychanalyse.

A partir de 1952, ano da primeira cirurgia de transgenitalização bem-sucedida, o tema da transexualidade tem suscitado grandes discussões, envolvendo diferentes campos do saber e da cultura, tais como: o movimento político LGBT (lésbicas, gays, bissexuais, travestis e transexuais); a medicina, por meio das intervenções hormonocirúrgicas; os teóricos da identidade de gênero e a psicanálise.

Catherine Millot, em seu livro Extrasexo (Millot, 1992), sublinha que os primeiros casos de transexualidade relatados pelos psiquiatras e sexólogos pareciam tratar-se de casos de psicose, no entanto hoje esse tema está longe de ser vinculado apenas ao campo das psicoses. Neste trabalho, procuramos abordar o conceito de transexualidade, traçando o percurso da construção do diagnóstico transexual, assim como apresentar as elaborações teóricas a respeito da diferença sexual na perspectiva da psicanálise, trazendo alguns fragmentos de casos que possibilitem a discussão do tema.

\section{Da Patologia Transexual ao Fenômeno da Transexualidade}

Na obra de 1886, Psicopathia sexualis: As histórias de casos, o médico Richard Von Krafft-Ebing (2001) apresenta alguns casos que poderiam indicar o atual diagnóstico transexual em um momento anterior às primeiras experiências cirúrgicas de transformação genital. Krafft-Ebing entendia como um distúrbio qualquer prática sexual sem fins reprodutivos e buscava uma cura para as patologias sexuais, visando um ideal sexual, como se houvesse uma sexualidade dita normal. Todavia o valor de sua obra se dá pela ilustração e pela descrição de seus casos clínicos, sendo indiscutível sua influência na construção dos diagnósticos psiquiátricos no que se refere à sexualidade. Nessa obra, Krafft-Ebing apresenta uma autobiografia, em que o remetente narra sua experiência de identificação com o sexo feminino. Esse caso nos parece ser emblemático para pensarmos os primórdios do que atualmente se designa como transexualidade no campo médico.

O autor da carta conta que, em sua infância, tinha uma relação muito próxima com sua mãe e que as pessoas diziam que ele não havia sido feito para ser um menino. Tomava cuidado para não demonstrar a preferência pelas coisas femininas, principalmente no que diz respeito às vestimentas. Aos 12 anos, sentia coceira, ardência e contrações, que iam do pênis até as costas. Relata que the agradavam as formas, os modos e, em particular, as roupas das jovens senhoras. Ele menciona: "tomava cuidado, porém, para que isso não fosse notado, mas tenho certeza de que não me teria esquivado da faca de castração se dessa forma pudesse satisfazer meus desejos" (Von Krafft-Ebing, 2001, p.145).

Afirma não ter inclinações por homens e que talvez seu desejo fosse de que ambos (o paciente e a parceira sexual) fossem mulheres. Aos 18 anos, começou a nascer barba e ele passou a ter feições mais masculinas. Durante a faculdade, teve relações sexuais com mulheres e, sobre essa experiência, diz: "eu só queria ficar debaixo da moça, trocando meu pênis por sua vagina. Para seu espanto, ela teve de me tratar como uma moça e o fez de bom grado; mas me tratou como se eu fosse ela" (Von Krafft-Ebing, 2001, p. 147). Já lhe havia ocorrido pensamentos em que ele sentia atração por si mesmo.

Gradualmente, passou a sentir-se como uma moça. Tentou suicídio duas vezes, passou quatorze dias sem dormir, apresentou alucinações auditivas e visuais, pensava estar entre os vivos e os mortos, pensamentos que continuaram ao longo de sua vida.

Casou-se a contragosto devido a circunstâncias familiares e, sobre a noite de núpcias, diz: "senti que era apenas uma mulher na forma de homem; sob a minha pele jazia uma mulher" (Von Krafft-Ebing, 2001, p.149). Relata que, desde o primeiro coito, a posição masculina lhe era repugnante e difícil e que, após alguns anos, se tornou neurastênico. Em uma dessas crises, sentiu subitamente a sensação de se aproximar da morte e, então, afirma ter experienciado a sensação de ser exatamente como uma mulher, com pulsões sexuais femininas. "De repente me vi como uma mulher dos pés à cabeça; senti, assim como antes no banho, que meus genitais tinham encolhido, a pelve se alargara, os seios inchavam; um indescritível sentimento de prazer 
tomou conta de mim." (Von Krafft-Ebing, 2001, p.150). Na manhã seguinte, passou por uma experiência delirante de ter a sensação de acordar com o corpo inteiro transformado em mulher, inclusive com a percepção de possuir uma vulva e seios. "Tenho o desejo de ser assexuado, ou de eliminar em mim qualquer sexo. Se fosse solteiro, já teria há muito tempo extirpado o testículo, escroto e pênis." (Von Krafft-Ebing, 2001, p.156).

Evidencia uma total submissão ao imperativo de ser feminino: "quando o sentimento feminino reaparece, ele exige imperativamente reconhecimento. Muitas vezes é satisfeito com uma concessão moderada, como usar um bracelete sobre o punho; mas exige imperativamente alguma concessão. Só me sinto feliz quando me vejo vestido de mulher" (Von Krafft-Ebing, 2001, p.158).

Esse relato, citado por Krafft-Ebing em 1886, parece enquadrar-se bem naquilo que Harry Benjamin vai formular conceitualmente muitos anos depois. Harry Benjamin foi o principal responsável pela nomeação e pela conceituação do transexualismo. Sua produção sobre o tema inicia na década de 50 do século passado e, em 1966, publica The transexual phenomenon, onde diz que:

Os verdadeiros transexuais sentem que eles pertencem ao outro sexo, eles querem ser e funcionar como membros do sexo oposto, não apenas parecer como um. Para eles, seus órgãos sexuais, o primário (testículos), assim como o secundário (pênis e outros) são repulsivas deformações que devem ser modificadas com a faca do cirurgião. (Benjamin, 1966, p. 11) [tradução nossa] ${ }^{1}$

O autor afirma que o desejo de mudar de sexo é conhecido há muito tempo por psicólogos e psiquiatras, mas somente com os avanços da endocrinologia e com as técnicas cirúrgicas essa situação pôde ser modificada. Segundo ele, as terapias que visam os transexuais a conformar-se com seus corpos são fadadas ao fracasso, pois o pensamento dos transexuais não muda e todas as tentativas que visavam esse efeito falharam.

Stoller, psicanalista norte-americano, foi também um dos pioneiros a trabalhar com o tema da transexualidade na década de 1970, sendo o responsável por introduzir na psicanálise a discussão sobre a distinção entre sexo e gênero. Ele propõe um tratamento voltado a uma reeducação dos transexuais e pondera: "não posso fazer nada além de acreditar que quanto mais tempo a feminilidade estiver presente, menores são as chances de removê-la por qualquer técnica" (Stoller, 1982, p. 278). Nota-se em Stoller a ambição de reverter o quadro transexual, considerando esse objetivo como o sucesso do tratamento terapêutico, mas, ao mesmo tempo, o autor se posiciona contra aqueles que acreditam que a "transformação sexual" nunca é indicada. Ele entende que, se não é possível reverter o quadro transexual, então lhe é designado o tratamento hormonocirúrgico. Diz ele:

$\mathrm{Na}$ ausência de tal tratamento, temos três escolhas: 1. insistir, apesar de tudo, que eles sejam tratados por algum método que não funciona (psicanálise); 2. não fazer nada, com ou sem exortação moral; 3. providenciar-lhes a "transformação sexual". Tenho sido, para esses pacientes, a favor da terceira. (Stoller, 1982, p. 249)

Nota-se que o autor não abre espaço para a possibilidade de um sujeito habitar um corpo que não irá corresponder com determinados padrões estabelecidos para o masculino e o feminino e, assim, poder escutar as saídas encontradas de maneira singular pelo sujeito nessa conflituosa relação com o corpo próprio.

Millot (1992) afirma que, em certo sentido, não havia transexualismo antes de Benjamim e Stoller a terem inventado, o que havia eram os delírios e a metamorfose sexual, descritos anteriormente por Von Krafft-Ebing (2001). A partir do momento em que a ciência inventa procedimentos que "respondem" à questão do transexual sobre a sua certeza de pertencer ao outro sexo, vão se produzindo discursos no laço social, tornando a transexualidade um sintoma social com uma maleabilidade sintomatológica. Nesse sentido, os pioneiros nos estudos da transexualidade construíram uma identidade transexual e uma certeza de que a cura para o mal-estar da transexualidade é a mudança de sexo.

Clavreul (1983), em A ordem médica: Poder e impotência do discurso médico evidencia a função silenciadora do discurso médico, inclusive para o próprio médico, o qual se anula enquanto sujeito diante das exigências da objetividade científica. Em 1966, Lacan profere uma conferência intitulada O lugar da psicanálise na medicina (Lacan, 2002) e afirma que o lugar da psicanálise no campo médico apresenta uma relação direta com as mudanças produzidas na função e no personagem do médico. Sublinha que, no século XIX, as doutrinas médicas passaram a se proclamar científicas, mascarando o que anteriormente se localizava como uma espécie de filosofia. A passagem da medicina para a ciência não se limita ao fato de que se tenha introduzido nesse campo a exigência da condição experimental, pois o organismo humano sempre foi objeto de experimentações. No entanto tais experimentos passam a ser entendidos como se não pudessem ser apreendidos sem as condições laboratoriais, elevando-se, dessa forma, ao status científico.

1 . O texto em língua estrangeira: True transsexuals feel that they belong to the other sex, they want to be and function as members of the opposite sex, not only to appear as such. For them, their sex organs, the primary (testes) as well as the secondary (penis and others) are disgusting deformities that must be changed by the surgeon's knife. 
Diversas terapêuticas são construídas pela ciência, que solicita ao médico que coloque à prova seus novos produtos. Para Lacan (2002), é nesse ponto que ocorrem as transformações na relação do médico com aqueles que se endereçam a ele. O desenvolvimento científico inaugura uma organização mundial que coloca em primeiro plano o direito do homem à saúde, oferecendo a possibilidade de pedir ao médico uma resposta objetiva e imediata.

Dissemina-se a ideia de que a escolha do sexo pode se concretizar com as promessas dos avanços da medicina. A noção de identidade de gênero passa a ser vista como algo que está para todos e é entendida como o desejo de cada um de pertencer a determinado gênero. O sexo fica reduzido à dimensão de uma aparência e, dessa forma, se constrói a ilusão de que ele é passível de transformações.

Frignet (2002), no segundo capítulo de seu livro $O$ transexualismo, apresenta o caso de George Jorgensn, ex-soldado americano que se torna Christiane Jorgensen. Sua história foi publicizada em 1952 e marca a primeira experiência bemsucedida de intervenções hormonais e cirúrgicas, despertando um grande interesse midiático que, a partir de então, passa a desempenhar um papel fundamental na divulgação e na expansão da transexualidade. Sendo assim, é importante salientar que a divulgação das "novas formas da sexualidade" e das intervenções hormonocirúrgicas pelos meios de comunicação produzem efeitos discursivos no sujeito, o que pode vir a resultar em uma maleabilidade clínica do sintoma transexual, encontrando novas expressões. Nesse sentido, vários significantes são produzidos para tentar nomear um sujeito que não se identifica com o gênero que seu sexo anatômico indica: transexual, travesti, transgênero.

A psicanálise não trabalha com os gêneros homem e mulher enquanto categorias que definiriam o sujeito, tampouco reduz essa questão ao âmbito biológico, macho e fêmea, mas entende que a anatomia do corpo produz consequências psíquicas, ao mesmo tempo em que o corpo não é dado a priori. Ele se constitui a partir da linguagem e do encontro com o outro e, dessa forma, habitamos um corpo em suas dimensões real, simbólica e imaginária (Lacan. 2005 e Lacan, s.d.) ${ }^{2}$. Ficamos capturados pela imagem de nosso corpo e é ele que nos confere uma consistência que nos introduz na economia do gozo. O real produz furos nessa imagem, que a palavra tenta contornar, deixando sempre um resto, por isso "a incongruência entre a linguagem e o corpo está na origem do sintoma, cujo sentido deriva do encontro com a realidade sexual nas primeiras experiências infantis" (Rinaldi, 2011), p.441).

$\mathrm{Na}$ fala dos sujeitos que se reconhecem como transexuais estão presentes diversos modos de se relacionar com o corpo próprio. Alguns relatam usar apenas roupas e adereços do sexo oposto, outros fazem uso somente do tratamento hormonal e há, ainda, aqueles que desejam modificar completamente o corpo através de recursos hormonocirúrgicos. Entende-se que existe uma diferença que não deve ser banalizada entre aqueles que não buscam esses recursos da medicina e aqueles que rejeitam seus próprios corpos e se submetem a diversos procedimentos para transformá-lo em outro.

Nesse sentido, cabe retomar o que a psicanálise apresenta sobre a diferença sexual a fim de avançar na discussão dessa questão tão complexa.

\section{Sobre a Diferença Sexual na Psicanálise}

Freud trabalha o tema do masculino e do feminino em diversos textos e em diferentes momentos de sua obra, como em: Fantasia histérica e sua relação com a bissexualidade (1924/1996a), A dissolução do complexo de Édipo (1908/1996b) e A sexualidade feminina (1931/1996c). Ao desenvolver o conceito de complexo de Édipo, importa-se em diferenciar o que ocorre nos meninos daquilo que ocorre nas meninas, e mostra como a saída do Édipo irá implicar em identificações com ambos os genitores. $\mathrm{O}$ autor salienta que a diferença entre os sexos não é dada a priori, ela se constitui após diversas descobertas e construções teóricas infantis acerca da sexualidade.

No entanto é importante frisar que essas construções são feitas a posteriori, pois Freud aponta a existência de uma bissexualidade universal, que diz respeito ao investimento da libido em ambos os sexos. O que ocorre, muitas vezes, é que um dos lados dessa escolha de objeto irá se destacar, enquanto o outro permanecerá latente. É interessante notar como, desde o início de suas construções teóricas, Freud já apontava para a não existência de uma sexualidade humana em que a escolha de objeto estivesse definida pelos opostos homem e mulher. O que está em jogo, para Freud (1923/1996d), é a primazia do falo, que não se reduz ao pênis.

Reconhecer-se na partilha dos sexos implica a travessia pelo Édipo e se constitui por meio de um mesmo referencial, o falo, que articula a sexualidade e a linguagem, deixando uma marca sobre o corpo. "O falo é um significante - logo, um

2 Real, simbólico e imaginário são os três registros da topologia da subjetividade nomeados por Lacan. É por meio desses registros - que se encontram sempre entrelaçados - que experienciamos a vida humana. Lacan define o imaginário a partir de uma operação que irá constituir a instância do eu, o estádio do espelho. O eu nos garante a ilusão da unificação de uma imagem por meio da identificação com a imagem do outro. O simbólico diz respeito ao campo da fala e da linguagem, a partir da incorporação de uma rede de significantes que possibilita a constituição do sujeito. Já o real é aquilo que escapa ao simbólico e ao imaginário, é algo impossível de ser representado. (Lacan. 2005 e Lacan, s.d.). 
semblante. O semblante sempre envelopa o vazio, fazendo crer a existência de algo que não há. $\mathrm{O}$ semblante, ainda que se esforce por ocultar, o que oculta é nada." (Costa \& Bonfim, 2013).

Antunes (2016, p. 53), em seu texto A anatomia é o destino: a psicanálise e o sintoma transexual, trabalha a questão do falo e sua incidência na diferença sexual a partir de dois pressupostos: o falo não é o pênis e o falo não é sem o pênis. "O ponto crucial a meu ver, do ponto de vista psicanalítico, é que o simbólico só se transmite encarnado. São necessários um corpo como suporte e um desejo que não seja anônimo." Ela enfatiza que no inconsciente só existe a inscrição do falo, e é no registro imaginário que o homem e a mulher aparecem enquanto oposição, com qualidades contrárias. No registro simbólico, o falo orienta a diferença sexual no nível estrutural da diferença significante. "A existência da alteridade como irredutível, impossível de se dissolver na igualdade" (Antunes, 2016, p. 53). O Outro sexo é aquilo que resiste à identificação, aquilo que não se reduz à oposição imaginária homem-mulher.

Lacan (2012), no Seminário 19: ...ou pior, diz: "não é que eu negue a diferença que existe, desde a mais tenra idade, entre o que chamamos de uma menina e um menino. É inclusive daí que parto" (Lacan, 2012, p. 13). Mais à frente, ainda nesse seminário, Lacan aponta que "conforme ao tipo característico do homem e da mulher, tais como eles se constituirão a partir de algo completamente diferente, a saber da consequência, do preço que terá adquirido, na continuação, a pequena diferença" (Lacan, 2012, p. 16).

Os corpos dos seres humanos, de maneira geral, se dividem anatomicamente em dois (homens e mulheres), de forma quantitativamente semelhante, no entanto o que Lacan atenta é que essa distinção não se faz por si só. Somos nós que fazemos essa diferença, na medida em que ela é transmitida pelo Outro no que tange aos efeitos do que se deseja para um menino ou a uma menina, e que isso se apoia em um erro. "Esse erro consiste em identificá-los, sem nenhuma dúvida, por aquilo pelo qual eles se distinguem, mas em reconhecê-los somente em função de critérios formados na dependência da linguagem." (Lacan, 2012, p. 16).

Para Antunes (2016), a anatomia se impõe à medida que ela serve de suporte do corpo ao real. Trata-se da tentativa de construção de uma interpretação do real pela via do simbólico. Isso vai possibilitar a articulação entre corpo e semblante. De acordo com Antunes, não se trata de abordar o transexual, e sim o sintoma transexual, assim como o que sustenta esse sintoma enquanto efeito do processo de sexuação. Nesse sentido, o sintoma transexual, assim como a feminilidade e a masculinidade, se constitui como sintoma que encobre a falta.

Lacan (1998a), em A instância da letra no inconsciente, apresenta duas portas de banheiro idênticas, sob as quais está escrito "homens e damas". Essa representação mostra como somos convocados a definir linguisticamente nosso sexo. O que Lacan ressalta com isso que chama chistosamente de "segregação urinária" é que a base da diferença sexual se encontra na materialidade da linguagem, criticando a noção de realidade que se baseia no anatômico, como se fossem nominados pelos representantes homem e mulher. Para isso, ele se utiliza dos termos homens e damas, evidenciando que a diferença é uma operação simbólica.

Existem, inclusive, algumas tentativas de utilizar na língua escrita o símbolo @ no intuito de não se submeter a uma escolha linguística que marque um gênero. Há também uma outra tentativa, pouco avançada, de escrever a letra "e" no lugar do "a" ou "o", por exemplo: não dizer bonito ou bonita, e sim "bonite", visando abolir essa diferença linguística. Todavia não se trata de quantas classes gramaticais podem ser usadas na Língua Portuguesa, há sempre algo da ordem do impossível de escrever sobre o sexo. A letra é a diferença material entre os significantes que produz efeitos de significação. A letra é o que resiste à simbolização, ela é a parcela de real da linguagem.

Em Além do princípio do prazer, Freud, (1920/1996e) retoma o mito de Aristófanes, que conta que, no princípio, não haveria apenas dois sexos, e sim três: o homem, a mulher e um terceiro tipo, uma espécie de união entre eles. Então Zeus decide separá-los em dois e, desde então, cada parte busca encontrar sua metade, a fim de fundirem-se. O mito de Aristófanes exemplifica uma concepção de complementaridade entre os sexos que Lacan vai desconstruir com as fórmulas da sexuação.

Ele assinala que o falo é o significante que organiza o campo sexual e é com relação a ele que nos posicionamos enquanto homens ou mulheres. "É justamente como significantes que vocês se tornam sexuados" (Lacan, 2012, p.31). As fórmulas da sexuação são construídas a partir de uma lógica composta por quatro proposições que determinam a posição sexual de todo ser falante. Duas delas caracterizam o lado homem e as outras duas, o lado mulher. Todas elas dizem respeito à maneira de se relacionar com a função fálica. Nesse sentido, não se trata de uma relação dual, como é narrado no mito de Aristófanes, mas uma relação ternária: homem, mulher e falo.

Lacan (2012) observa que a posição masculina diz respeito a uma relação com o falo que se apresenta na ordem do ter, ao passo que a posição feminina diz respeito à ordem do ser. A posição masculina irá estabelecer uma relação com o objeto, como sendo este a causa de seu desejo, um objeto que irá representar o falo, o que nos leva à posição feminina, que remete à dimensão do ser. Em A significação do falo (Lacan, 1998b), o autor afirma que, acima de tudo, ser homem ou mulher é da ordem do semblante, um "parecer" ser homem ou mulher. São características típicas e idealizadas de cada sexo que vão constituir um certo saber sobre eles.

Para pensar a dimensão do semblante em psicanálise, é necessário sair da oposição do verdadeiro e do falso, pois, como vemos em Lacan (2009), a verdade não é absoluta, ela só pode ser "semi-dita". Sendo assim, tudo que é linguagem, 
é semblante. Na construção das fórmulas da sexuação, Lacan (2008b) nomeia um lado de homem e o outro, de mulher. No entanto essa nomeação não se refere aos seres nascidos do sexo masculino ou feminino. Tais posições dizem respeito a duas modalidades de gozo, e poderiam ser pensadas, respectivamente, como o 'lado todo fálico' e o 'lado não todo fálico'.

É importante também destacar que essas posições não se limitam ao par heterossexual. Todo ser falante se inscreve de um lado ou de outro, e Lacan (2008) frisa que essa inscrição é da ordem de uma necessidade e não de uma contingência, isto é, diz respeito a uma escolha forçada, paga pelo sujeito. "Tais são as únicas definições possíveis da parte dita homem ou bem mulher para o que quer que se encontre na posição de habitar a linguagem" (Lacan, 2008b, p. 86).

O lado homem apresenta a afirmativa universal de que todos os homens estão relacionados à função fálica e essa proposição universal é fundada por outra proposição que a nega, que existe ao menos um que não está submetido à função fálica. O todo, para se constituir, necessita de uma exceção, isto é, não há um dentro sem que haja um fora. Esse ao menos Um que não está submetido à castração diz respeito ao lugar do pai primitivo, descrito por Freud (1913/1996f) em Totem e tabu, que gozaria de todas as mulheres. "A função do Pai consiste ao mesmo tempo em dar consistência ao mito de um gozo absoluto que ele encarna e em situar este gozo como proibido e inacessível: a função fálica se fundando sobre a exclusão lógica desse gozo" (Millot, 1992, p. 34). Nesse sentido, o universal do lado homem se caracteriza pela castração, pela exclusão desse gozo absoluto.

O lado mulher pode ser entendido como não existe nenhuma mulher para quem a função fálica não opere, no entanto é à mulher não toda que está referida a lógica fálica, ou seja, nem tudo está submetido à lei do significante. A exclusão lógica do gozo absoluto não produz uma totalidade no lado mulher: nenhum universal pode se constituir, as mulheres não são coletivizáveis, não formam um todo. As mulheres, ao mesmo tempo, têm e não têm relação com o falo e com a castração. Nada faz limite à função fálica e, consequentemente, há um gozo diverso do lado homem, o Outro gozo, que não fálico.

O lado todo e o "não-todo" não significam uma oposição; o "não-todo" está referenciado à função fálica, mas a ultrapassa. Por não ter ao menos um que forme uma exceção, a constituição de um conjunto se faz impossível. Nesse sentido, o aforisma lacaniano "a mulher não existe" aponta que é impossível abordar a mulher em termos coletivos, abrindo o caminho para a singularidade, pois a psicanálise toma o sujeito no um a um.

\section{O que a Clínica nos Ensina}

Para avançar no debate atual sobre a transexualidade, levando em conta a orientação da clínica psicanalítica, assim como seus pressupostos teóricos relativos à diferença sexual, traremos alguns fragmentos de casos que foram acompanhados por meio de dispositivos dos serviços públicos de saúde mental, cuja clínica é destinada a pessoas em intenso sofrimento psíquico que, em grande parte, são sujeitos psicóticos. Sendo assim, serão apresentados três fragmentos de casos ${ }^{3}$, com hipótese diagnóstica de psicose, em que a transexualidade se apresenta de diferentes formas. Importante esclarecer que, ao longo do texto, as referências à transexualidade estão relacionadas à clínica das psicoses, mas sabemos que as diferentes estruturas nos impõem diferentes direções de tratamento.

\section{Leandro e o Empuxo-à-Mulher}

Leandro chega ao Caps vestindo uniforme de jogador de futebol e diz que vai jogar na Copa do mundo. Relatava ser argentino, filho de atores do SBT e apresentava alucinações auditivas, em que conversava constantemente com uma câmera.

Quando começo a atendê-lo, descubro que ele já frequentava o Caps diariamente e, logo no início, mostra uma pasta com todos os seus desenhos, produto da oficina de "simbolização". Entre os diversos desenhos, havia um desenho em especial que era todo em cor-de-rosa e nomeado por ele de "mundo gay". Leandro conta que escuta vozes, o chamando de gay, e relata, com sofrimento, o desejo de não ser gay. Refere que tudo isso começou na última Copa do Mundo, em 2010. Durante os jogos do Brasil, passou a ter um interesse pelas coxas dos jogadores e diz ser esse o assunto que ele tem que tratar.

Relata que, quando adolescente, começa a se envolver com o tráfico, mas essa relação não durou muito. Ainda em sua adolescência, sua mãe se juntou com uma mulher e, neste período, diz ter sido alvo de chacotas na escola por ter uma mãe lésbica. Essa situação o deixou extremamente incomodado, levando-o a sair de casa. Trabalhava como entregador de água e morava em um hotel no centro da cidade, contudo foi demitido e passou a vender balas e doces pelos ônibus. Mesmo com essa atividade, não conseguiu sustentar o pagamento do hotel, passando, desse modo, a morar na rua.

Leandro se vinculou a uma igreja evangélica e, para frequentar esse espaço, usa sempre um terno, que diz ser a vestimenta masculina, diferente das saias, que são vestimentas femininas. Conta que, às vezes, seu corpo se transforma em corpo de mulher. Segundo ele, isso ocorre principalmente quando vai tomar banho, e pode-se supor que é um momento em que se encontra sem

3 Os fragmentos de casos dizem respeito a acompanhamentos clínicos realizados em fase anterior à pesquisa que deu origem a esse artigo. Os nomes utilizados são fictícios, tendo em vista a preservação do sigilo quanto à identidade dos usuários dos serviços. 
suas vestes e, portanto, sem um contorno corporal. Outro relato em que se refere ao mesmo fenômeno feminilizante ocorre quando fala sobre um período de sua vida, em que usava luvas e imitava o Michael Jackson. No momento em que retirava as luvas, suas mãos ficavam femininas. Todavia, segundo Leandro, mesmo sendo mais frequente a transformação corporal nesses momentos, ocorre também em algumas situações cotidianas e de maneira inesperada.

É nesses momentos que ele recorre ao uso do terno, por ser uma vestimenta tipicamente masculina e por cobrir quase todo o corpo, utilizando-o como um recurso a fim de dar ao seu corpo o contorno de um corpo de homem. É interessante notar no relato de Leandro como a diferença entre os sexos se resume a vestimentas vazias.

O relato de Leandro nos leva à hipótese diagnóstica de psicose, tendo em vista que, na falta de um recurso simbólico que advém da significação fálica, ele se sustenta por identificações imaginárias que vão deslizando: jogador de futebol, traficante, religioso, Michael Jackson etc.

Diante da experiência de ter um corpo, o qual de súbito apresenta formatos femininos, Leandro usa o terno como um recurso para não ficar à mercê desses fenômenos e é dessa forma que ele dá contorno ao corpo.

Essa experiência de feminilização corporal, presente em Leandro, nos remete ao caso Schreber, trabalhado por Freud (1911/1996g) em Notas psicanalíticas sobre um relato autobiográfico de um caso de paranoia. No primeiro momento, Schreber fica à mercê de um gozo insuportável que invade seu corpo, transformando-o em mulher e reduzindo-o a um objeto para fins sexuais dos homens. No segundo momento, a construção delirante de ser a Mulher de Deus possibilita a restauração do imaginário e tem a função de ponto-de-basta, vindo a suprir o Nome-do-Pai que fora foracluído. A partir dessa amarração, se institui uma ordem delirante, que irá permitir ao sujeito atribuir significação aos seus significantes.

Lacan (1998c), em sua releitura freudiana, vai retomar o delírio de Schreber enquanto uma prática transexual, apontando que a posição do sujeito psicótico de identificação com o falo imaginário da mãe o impulsiona a uma feminilização, que denomina de empuxoàmulher. Em Uma questão preliminar a todo tratamento possível da psicose, Lacan diz: "como podemos perceber, ao observar que não é por estar foracluído do pênis, mas por ter que ser o falo, que o paciente estará fadado a se tornar mulher." (Lacan, 1998c, p.571).

Assim como Schreber, Leandro experimenta um gozo que diz respeito à transformação de seu próprio corpo em um corpo feminino. No caso de Schreber, a construção delirante não retira o sujeito de sua posição de objeto de gozo do Outro, no entanto permite localizar e dar um contorno ao gozo, na medida em que seu corpo fica sob a influência de Outro gozador, encarnado na figura de Deus.

Leandro tem a tarefa de delimitar um corpo sem a regulação fálica, isso exige que o sujeito faça amarras e invenções. Ele não constrói um recurso delirante, busca barrar o gozo que o invade na utilização da própria roupa enquanto um veículo de estabilização de sua imagem, dessa forma, ele faz um corpo, delimitando seus contornos.

O caso de Leandro nos ensina que a identidade sexual não é uma questão que seria dada a partir de uma clínica específica com os transexuais que incluem intervenções no corpo, mas diz respeito aos dilemas de um sujeito na difícil tarefa de constituir-se e sustentar-se a partir de um semblante.

\section{Luciano e a Diferença Sexual}

A construção desse caso foi possível a partir das discussões realizadas nas reuniões de equipe em um Caps de um grande centro urbano. $\mathrm{O}$ acompanhamento de Luciano se resumiu aos espaços de convivência da instituição, visto que ele se recusava a ser atendido por mulheres.

Luciano nasceu mulher e não sabíamos muito bem como ele passou a assumir a identidade masculina. Ele possuía a aparência e o tom de voz masculino e, se não fosse o fato de possuir seios avantajados, passaria facilmente por um homem. Já tendo ficado em situação de rua, teve uma vivência bastante marcada por esse espaço e por uma rede de pessoas conhecidas que habitam as ruas da região do centro da cidade.

Logo em sua inserção na instituição, Luciano faz uma relação transferencial importante com um psicólogo, um dos poucos homens da equipe. Nos momentos em que permanecia nos espaços de convivência, não se relacionava com mulheres, tanto profissionais quanto usuárias, conversando com elas apenas questões objetivas e necessárias, como horário de funcionamento, questões sobre alimentação etc. Parecia escutar muitas vozes, apresentando um olhar distante em alguns momentos e, em outros, dava risadas aparentemente sem motivo, o que se pode supor serem respostas às escutas alucinatórias.

Segundo relatos do profissional que o acompanhava mais de perto, ele passava muitas sessões descrevendo seu próprio pênis, dizendo o quão grande e potente ele era. Relatava também encontros sexuais com outros homens, sendo que a profissão desses parceiros sempre estava diretamente relacionada com a utilização da força física, como é o caso dos bombeiros ou dos policiais. No que diz respeito à assunção de sua identidade, contava sobre sua vida como se fosse alguém nascido do sexo masculino e não se reconhecia como um transexual. Sua identidade masculina era inquestionável. 
A relação transferencial com o psicólogo se deu de forma maciça, a ponto de Luciano passar todo seu tempo na instituição tentando permanecer na presença desse profissional. Em um dado momento, ao ser questionado sobre sua insistência em falar sobre seus órgãos genitais, Luciano se irrita e tenta agredir seu psicólogo, como se essa pergunta colocasse em questão toda a sua identidade masculina.

Tanto a presença do psicólogo homem como imagem especular quanto o ato de descrever seu próprio corpo, a partir de uma construção delirante, oferecia a ele a sustentação de uma imagem. Ao questionar seu delírio, cujo conteúdo remetia à própria estruturação de seu corpo, responde com o recurso agressivo. Lacan (1998d), em A agressividade em psicanálise, assinala que "essa relação erótica, em que o indivíduo humano se fixa numa imagem que o aliena em si mesmo, eis aí a energia e a forma donde se origina a organização passional que ele irá chamar de seu eu” (Lacan, 1998d, p. 116).

O autor aponta que não há identificação sem agressividade, assim como não há agressividade sem identificação, e a situa na especularidade imaginária. Todavia há uma diferença entre a agressividade, constituinte de toda relação com o outro, e o ato agressivo. "A violência é de fato o que há de essencial na agressão, pelo menos no plano humano. Não é a fala, é até exatamente o contrário." (Lacan, 1999, p. 471). Ali, onde a construção delirante sustentava o imaginário do corpo, houve uma ruptura que não foi possível ser recoberta pela via da palavra, restando o ato agressivo.

Alguns usuários do Caps que estavam em situação de rua comentavam que, às vezes, durante a madrugada, encontravam Luciano andando pelas ruas de salto alto e batom, oferecendo-se para programas sexuais. Entretanto, no dia seguinte, Luciano chegava ao Caps como um homem, recusando qualquer diálogo que pudesse negar sua posição masculina.

Nesse momento, uma nova proposta de trabalho em grupo começou a ser implementada no Caps, chamada de Oficina de autocuidado, em que ficavam disponíveis produtos de higiene pessoal e maquiagem para qualquer um que desejasse utilizar. Luciano participou dessa oficina, maquiou-se, e procurou seu psicólogo dizendo que era, na verdade, uma mulher. Não se dispondo a falar mais sobre isso, Luciano retornou à instituição no dia seguinte, vestido como homem e sem fazer nenhuma referência ao dia anterior.

Logo em seguida, seu psicólogo encerrou seu trabalho no Caps e Luciano não retornou mais à instituição. Após alguns meses, a equipe do Caps recebeu um telefonema, de outro serviço de saúde mental, dizendo que Luciano havia retornado a sua cidade natal. Ele contou toda sua trajetória pelo Caps e solicitou que os avisassem sobre seu paradeiro e sobre sua nova identidade, que passou a ser feminina, vindo a se chamar Luciana. Contudo isso também não se sustentou. Segundo o irmão, o reconhecimento de Luciano de pertencer ao grupo das mulheres voltou a oscilar. Ele passa a maior parte do tempo como homem, sendo que, apenas em alguns momentos, faz uso das joias e roupas femininas e se refere a si como mulher.

A oscilação de Luciano sobre sua identidade sexual diz respeito a uma sexualidade que não tem a referência fálica como ordenadora, visto que a travessia pelo Édipo é condição necessária para se situar na partilha dos sexos. O que retorna para ele é uma certeza delirante de ser de um sexo ou de outro, no entanto, sem a construção de uma metáfora delirante que funcione como Nome-do-Pai e que possibilite um tipo de amarração dos três registros, sua imagem se apresenta instável. A diferença entre os sexos se resume a frágeis identificações imaginárias que não permitem que ele se sustente em uma identidade masculina, nem feminina, permanecendo nesse trânsito entre ser homem e ser mulher.

\section{Camila e a Transexualidade}

Camila decide sair de casa aos dezoito anos, pois sua mãe não permitia que ela se vestisse como mulher. Nascida do sexo masculino, foi morar com uma amiga que, segundo ela, era alguém que a ensinava sobre as coisas da vida. Camila conta que, certo dia, foi pega com uma grande quantidade de maconha. Esse fato a levou para a prisão, na qual permaneceu por dois anos. Recebia apenas a visita da mãe e, logo que saiu da prisão, foi à procura de sua amiga que, no entanto, já não se encontrava mais no local em que moravam e as duas nunca mais se viram. Foi a partir desse momento que Camila passou a se chamar com o atual nome feminino, que, na realidade, era o nome dessa amiga.

Ela conta que ficou sabendo por um jornal que a cirurgia de mudança de sexo já estava acontecendo no Brasil pelo Sistema Único de Saúde e iniciou sua busca para realizá-la. A partir daí, passa a ser acompanhada pela urologia feminina, inicia a terapia hormonal e é submetida a uma castração química ${ }^{4}$. Camila relata que, a partir da utilização desses remédios, seu desejo sexual diminuiu a ponto de não ter mais ereções. Essa intervenção que, a princípio, é muito radical, para ela se apresentou como algo apaziguador, pois ter ereções a incomodava muito.

A atribuição de virilidade ao pênis tem uma relação direta com a significação fálica que, em sua ausência, reduz essa parte do corpo a um pedaço da carne. "Um órgão é um instrumento que só existe por sua função, que é sempre significante. No caso do transexual parece tratar-se mais de uma excrescência do que de instrumento de gozo.” (Rinaldi, 2011, p. 447).

$4 \quad$ O antiandrógeno é o medicamento responsável pela castração química. A sua utilização atenua o impulso sexual e inibe a função das gônadas responsáveis pela produção dos hormônios masculinos. 
É possível perceber essa ausência de significação sobre seu órgão nos relatos de Camila quando ela afirma "ele não me serve para nada", e também o apaziguamento produzido pela castração química a que se submeteu. Em sua fala: "ter ereção me incomodava muito".

Camila era acompanhada por várias instituições públicas, que incluem: saúde, assistência social e movimento LGBT, sendo que sua rotina consistia em circular por todos esses espaços. Também era frequente sua passagem pela emergência psiquiátrica, devido às tentativas de suicídio por meio do uso excessivo de medicamentos. Tais tentativas a levavam, muitas vezes, a internações psiquiátricas.

Em sua trajetória, ela conseguiu mudar o prenome em todos os seus documentos (a carteira de identidade, laudos médicos, o certificado de conclusão da escola etc.) e, no momento em que tocava em algum assunto referente ao seu sexo, à identidade e à escola, apresentava um documento, sustentando suas palavras. Logo que a conheci, mostrava com orgulho a carteira de identidade, na qual estava escrito seu nome e a marca do sexo feminino, e relatava que, aos domingos, chegava a passar o dia olhando para seus documentos, organizando-os.

Muitas vezes, suas sessões giravam em torno de questões relacionadas aos cuidados de seus cabelos e seus incômodos com o crescimento dos pelos da barba, que diz ter melhorado muito após o início da utilização dos hormônios.

Czermak (1991, p. 86) salienta que, na transexualidade, as vestes femininas apresentam qualidades próprias. O olhar e o dizer do outro que o reconhece como mulher oferece ao transexual um envoltório visível sustentado pelo prazer cutâneo, em que "o sujeito não se sustenta atrás de algo, mas na própria vestimenta e em seu efeito cutâneo: o de colocar à pele, diríamos".

Vemos em Camila sua satisfação em ser reconhecida como mulher perante a justiça ao acatar sua reivindicação de mudança de nome e sexo, assim como sua tentativa de construir um corpo que possa recobrir o real que fura o imaginário a todo momento, como na ereção do pênis ou no crescimento da barba.

Procurava-me em diversos espaços da instituição, solicitando atendimentos, agia da mesma maneira com outras psicólogas e assistentes sociais de diversas instituições. A importância desse espaço para ela parecia, muitas vezes, marcada pela necessidade da presença de uma mulher, a partir de quem ela pudesse se sustentar imaginariamente. Czermak (2016) aponta que, com frequência, ao se depararem com uma mulher que consideram suficientemente mulher, os transexuais querem ser eles mesmos essa mulher, a imagem do eu ideal que, em sua ausência, dá origem à angústia.

Em um dos atendimentos, conta que foi à Parada Gay distribuir camisinhas junto ao grupo LGBT. Refere não ter se sentido muito bem, pois havia um grande número de pessoas. Relata que, quando estava em locais com muita gente, sentiase apática, estranha e não sabia quem era. Essa experiência de despersonalização que aponta para um corpo com falhas em seu continente também está presente no relato de um sonho, em que um alienígena aponta uma arma em sua direção e ela, que é feita de papel, se despedaça.

A presença de muitas pessoas era insuportável para ela, assim como também era insuportável a falta da presença do outro. Como nos indica Czermak (1991), na falha do imaginário se produz a angústia de despedaçamento, estados de pânico, profundos quadros depressivos e suicidas. Nos momentos em que o sujeito se coloca como dejeto, a cirurgia pode entrar como um recurso a fim de mudar a identidade.

Após seis anos de acompanhamento pela urologia, Camila é convocada para se internar em um hospital para realizar a cirurgia.

Há autores, como Millot (1992), que aproximam o gozo feminino do gozo do Outro do psicótico, utilizando-se das fórmulas da sexuação de Lacan. No lado mulher, a falta de limite à função fálica resulta em uma carência, tanto daquilo que vem a desencorajar o sujeito a se identificar com o falo imaginário quanto daquilo que interdita o gozo absoluto, assemelhando, dessa forma, a posição feminina a do psicótico.

No entanto Millot (1992) considera que, na transexualidade, acontece algo mais específico que a feminilização induzida pela psicose. O transexual "puro" não comporta sintomas psicóticos como são descritos pela psiquiatria. Nesse aspecto, a autora diz ser necessário diferenciar a posição transexual da posição da psicose, como no caso de Schreber. A autora apresenta uma hipótese de que o sintoma transexual, entendido como a convicção de ser A Mulher, e a demanda de transformação são tentativas de colocar um limite, um ponto de basta diante da carência do Nome-do-Pai. Esse enlaçamento seria um dos Nomes-do-Pai construído a partir d'A Mulher.

É importante destacar que o diagnóstico psicanalítico se diferencia do diagnóstico psiquiátrico, porque este se funda no saber fenomenológico, enquanto aquele apresenta uma referência estrutural. A psiquiatria constrói classificações nosológicas por meio de combinações de sinais e sintomas, enquanto a psicanálise realiza o diagnóstico (neurose, psicose e perversão) a partir da transferência e da relação do sujeito com a linguagem. A transexualidade é um diagnóstico psiquiátrico que, para ser assim diagnosticado, segundo o CID-10 (Organização Mundial da Saúde [OMS], 1997), é necessário que a transexualidade esteja presente por pelo menos, dois anos, e não deve estar associada a nenhum transtorno mental.

Nesse sentido, podemos encontrar muitos transexuais que, a partir do diagnóstico psicanalítico, são de estrutura psicótica. Eles se apresentam estáveis, justamente porque encontraram uma suplência pela via de ser $A$ Mulher, e, portanto, não apresentam, de maneira expressiva, os sintomas clássicos do campo das psicoses, como as alucinações e os delírios e, na falta 
desses sintomas, o psiquiatra pode não diagnosticar o transexual como um caso de psicose. Essa é a hipótese que levantamos no caso de Camila, que obteve a autorização para a cirurgia.

Ao ser visitada após sua operação, ainda durante o período de internação, estava bastante animada e expressiva, dizia estar muito feliz, ainda que relatasse sentir muitas dores no processo pós-operatório. Em um desses atendimentos, contou que passou por muitas internações psiquiátricas e que não permitiam que ela ficasse na enfermaria feminina, mas agora, que mudou seu nome e fez a cirurgia, se um dia precisasse, ela ficaria na enfermaria feminina.

Nas primeiras sessões, quando retornou para sua casa, relatava muita dificuldade em manter todos os procedimentos necessários para uma boa recuperação. Em alguns atendimentos, disse: "hoje, eu acordei e procurei meu peru para fazer xixi" e "não consigo encontrar o buraco da vagina".

Como parte de seu Projeto Terapêutico Singular, uma enfermeira começou a auxiliá-la em seus cuidados íntimos de limpeza e na utilização do dilatador. Era intensa a busca de Camila pela enfermeira, solicitando-lhe que visse seus novos órgãos genitais e confirmasse não haver nada errado ocorrendo com eles. Vemos a importância da dimensão do olhar para Camila, como nos indica Czermak (2016), ao lembrar que o olhar do Outro apresenta um duplo efeito: por um lado, pode se tornar um olhar persecutório, representante persecutório do Outro real que contesta seu ser mulher, e, por outro lado, o olhar lhe dá sustentação e lhe preserva das manifestações de despedaçamento corporal.

Esse duplo efeito do olhar também se apresenta em algumas sessões, em que fala sobre a diferença dos olhares em direção a ela, pois existiam olhares bons e olhares ruins. Quanto aos olhares bons, dava o exemplo de quando a pessoa era um cavalheiro e a deixava passar à frente em uma fila. Já os olhares ruins, eram os olhares que a discriminavam, como os das pessoas desconhecidas que a olhavam e sabiam que ela não tinha nascido do sexo feminino.

Seus atendimentos precisaram ser interrompidos com a minha saída do serviço. No entanto, depois de alguns meses, procurou-me, em meu novo local de trabalho, para me contar que usou calças e todos a elogiaram e que não lembrava mais a última vez em que havia usado calças. Após a cirurgia de redesignação sexual, após toda sua documentação apresentar nome e sexo feminino, os recursos imaginários que ofereciam contorno ao corpo despedaçado, como as vestes, inconfundivelmente femininas (os vestidos e as saias), já não se faziam mais tão necessários.

Não há dúvida de que o reconhecimento da diferença estrutural do sujeito impõe um tratamento diferenciado (Frignet, 2002). Nos sujeitos de estrutura psicótica, essas manifestações transexuais quase sempre indicam a possibilidade e a forma de reconstrução de laços com o mundo. Pode-se pensar essa reconstrução a partir do delírio de ser A Mulher, com base nas formulações lacanianas relativas ao nó borromeu e à suplência da função paterna, como nos mostra Millot (1992).

O nó borromeu concerne à articulação de três anéis, enlaçados de tal forma que se um deles se rompe, os outros dois também são rompidos. Esses anéis fazem alusão aos três registros propostos por Lacan (s.d.), a saber: o Real, o Simbólico e o Imaginário (RSI). Lacan introduz um quarto nó, que corresponde ao Nome-do-Pai, como um quarto elemento que entrelaça o RSI. A suplência diz respeito a outro significante, o qual pode vir a ocupar a função do quarto elemento, que é a de manter o nó. Na falta do Nome-do-Pai, o RSI poderia se romper sem que nenhum elemento os ligasse. Por essa perspectiva, A Mulher pode ser entendida como esse quarto elemento, mas que une apenas o Imaginário e o Simbólico, deixando o Real desenlaçado. Desse modo, segundo Millot (1992), a demanda transexual consiste em reivindicar que seja feita uma correção que ajustaria o Real ao nó do Imaginário e do Simbólico. O sintoma transexual apresentaria uma função de ordem estrutural, similar ao que Lacan sublinha na escrita realizada por Joyce.

Camila apresentava, em seu cotidiano, angústia de despedaçamento e ser A Mulher surge como uma possibilidade de reintegrar o corpo a partir da certeza de pertencer ao outro sexo. Nesse sentido, a cirurgia de transgenitalização pode não ter o intuito de inscrever no real do corpo a castração, mas, ao contrário, o recurso cirúrgico poderia ter a função de extinguir a marca do sexo e fazer existir $A$ Mulher.

No entanto, é importante salientar que, a construção de um corpo próprio, muitas vezes, requer um trabalho permanente do sujeito psicótico, pois é dessa forma que ele pode construir e manter a unificação de seu corpo e produzir uma estabilização. Assim como é necessário frisar que a construção delirante de ser A Mulher não passa necessariamente pela solicitação de uma cirurgia de transgenitalização, nem se reduz a ela. A estabilização da psicose, pela via da metáfora delirante de ser $A$ Mulher, pode vir a ocorrer sem a reivindicação de intervenções corporais. Nesse sentido, o sujeito pode encontrar e construir diversas saídas singulares para o seu mal-estar.

Segundo relatos de profissionais que deram continuidade ao tratamento de Camila, ela diz não ter se arrependido da cirurgia, contudo ela relata que sua vida não mudou muito e permanece com o mesmo movimento de circular pelas instituições públicas, à procura de atendimentos individuais. No Seminário 19: ...ou pior (Lacan, 2012), Lacan aponta que o transexual tenta se livrar do órgão na medida em que o confunde com o significante, ao que Czermak (1991), p. 89) acrescenta "pode-se, é verdade, desembaraçar-se do órgão, mas é mais difícil fazer o mesmo com o significante". 


\section{Considerações Finais}

Já apontamos que o tema da transexualidade incide em vários campos sociais e de saber, produzindo diversas formas de abordagem. No campo médico, no intuito de fazer "o bem" e acabar com o mal-estar do sujeito transexual, a medicina universaliza uma terapêutica e não reconhece os limites impostos pelo real do corpo e da diferença sexual e, assim, desconsidera os diferentes modos do sujeito saber-fazer com o real. Em seu lugar, oferece uma resposta que tampona o desejo do sujeito com uma promessa de felicidade. Lacan (2008a)nos adverte sobre a vontade de curar e de "fazer o bem" como algo suscetível a nos desencaminhar.

A medicina não escapa ao discurso do capitalista e, muitas vezes, se coloca a serviço dele, produzindo não apenas novas propostas de curas, como também novas categorias diagnósticas. Segundo Danziato, Lacan "postula a ideia de que o capitalismo teria estabelecido uma nova relação como o mais-de-gozar - análogo à mais-valia - na forma de uma capitalização desta recuperação do gozo" (Danziato, 2012, p. 156). Para aquilo que deveria ter sido renunciado e vivenciado como uma perda, o capitalismo oferece a recuperação na forma do objeto-mercadoria, o que tem como consequência o velamento do real da Coisa que marca o caráter eminentemente singular do sujeito e de sua forma de gozo. A questão se torna complicada na medida em que as intervenções hormonais e cirúrgicas passam a ser difundidas como sendo "a" terapêutica que trata dos transexuais de maneira generalizada e que desconsidera a subjetividade.

No que diz respeito ao movimento LGBT, uma questão se apresenta intrigante, pois a afirmativa que fundamenta muitas ações de tal movimento, qual seja: sexo e gênero se diferenciam, aponta uma contradição na transexualidade, na medida em que muitos transexuais almejam ardentemente modificar seu corpo para 'caber' no gênero com que se identificam. Antes, uma tentativa forçada de adequar os sujeitos ao seu sexo, agora adequar hormonal e cirurgicamente o sexo ao gênero. Uma perspectiva que continua sem abertura para construções singulares a respeito da inexistência da correspondência entre o sexo e o gênero, pois, afinal ninguém sabe o que é ser homem ou ser mulher. Só nos resta inventar.

A psicanálise é, muitas vezes, acusada de ir contra a diversidade sexual, o que é algo completamente oposto ao que, desde 1905, no texto os Os três ensaios sobre a teoria da sexualidade (1905/1996h), Freud afirmava, ao apresentar a sexualidade humana enquanto 'perversa polimorfa'. Mas o que a psicanálise nos ensina é que nem tudo é possível. É em direção ao real que uma análise é conduzida e, dessa experiência, se produz um efeito de desidealização. Sabe-se que é próprio da ética da psicanálise a afirmação de uma ética da diferença. Ela não promete o bem-estar das pessoas, tampouco propõe uma universalização moral das práticas sexuais. O que a psicanálise nos mostra é que não existe um objeto capaz de satisfazer por completo o desejo, mas é possível seguir um caminho desejante. O discurso do analista suporta escutar o lugar do impossível, sem tentar silenciá-lo ou tamponá-lo com saberes científicos.

Entendemos que a transexualidade incide de diferentes formas nas estruturas, mas é a partir da clínica que levantamos nossas questões e nossa experiência se deu, principalmente, no campo das psicoses. Essa clínica nos ensina de maneira escancarada a radicalidade da diferença e da singularidade. Nesse sentido, em uma perspectiva analítica, a diversidade sexual - tema tão caro ao movimento LGBT - diz respeito ao saber-fazer com o real do sexo, que é uma invenção singular que não se faz sem o outro, mas que, em última instância, é solitária, por isso única, sendo isso que a torna tão diversa.

\section{Referências}

Antunes, M. C. C. (2016). A anatomia é o destino: A psicanálise e o sintoma transexual. Revista aSEPHallus, 11(22), $42-67$.

Benjamin, H. (1966). The transexual phenomenon. New York: The Julian Press.

Clavreul, J. (1983). A ordem médica: Poder e impotência do discurso médico. São Paulo: Brasiliense.

Costa, A. M. M., \& Bonfim, F. (2013). O homem e A mulher na operação com o semblante. Revista aSEPHallus, 8(16), 134-147.

Czermak, M. (1991). Paixões do objeto: Estudo psicanalítico das psicoses. Porto Alegre: Artes Médicas.

Czermak, M. (2016). O transexualismo - pequena clínica portátil para o uso do psiquiatra contemporâneo. In M. Czermak, O corpo na psicose: Hipocondria, Cotard, transexualismov (pp. 177-186). Rio de Janeiro: Templo Freudiano.

Danziato, L. (2012). O gozo e o poder no seminário a ética da psicanálise de Lacan. Revista tempo psicanalítico, 44, 147-166. Link 
Freud, S. (1996a). Fantasia histérica e sua relação com a bissexualidade In J. Strachey (Ed), Edição standard brasileira das obras psicológicas completas de Sigmund Freud (vol.9, pp. 147-1560. Rio de Janeiro: Imago (Originalmente publicado em 1924)

Freud, S. (1996b). A dissolução do complexo de Édipo In J. Strachey (Ed), Edição standard brasileira das obras psicológicas completas de Sigmund Freud (vol. 19, pp.191-202). Rio de Janeiro: Imago (Originalmente publicado em 1908)

Freud, S. (1996c). A sexualidade feminina In J. Strachey (Ed), Edição standard brasileira das obras psicológicas completas de Sigmund Freud (vol. 21, pp. 231-254). Rio de Janeiro: Imago (Originalmente publicado em 1931)

Freud, S. (1996d). A organização genital infantil (uma interpolação na teoria sexual). In J. Strachey (Ed), Edição standard brasileira das obras psicológicas completas de Sigmund Freud (vol. 19, pp. 155-165). Rio de Janeiro: Imago. (Originalmente publicado em 1923)

Freud, S. (1996e). Além do princípio do prazer. In Edição standard brasileira das obras psicológicas completas de Sigmund Freud (vol. 18, pp. 13-156). Rio de Janeiro: Imago. (Originalmente publicado em 1920)

Freud, S. (1996f). Totem e tabu. In In J. Strachey (Ed), Edição standard brasileira das obras psicológicas completas de Sigmund Freud (vol.13, pp. 13-163). Rio de Janeiro: Imago (Originalmente publicado em 1913)

Freud, S. (1996g). Notas psicanalíticas sobre um relato autobiográfico de um caso de paranoia (uma interpolação na teoria sexual). In Edição standard brasileira das obras psicológicas completas de Sigmund Freud (vol. 12, pp. 15-92). Rio de Janeiro: Imago. (Originalmente publicado em 1911)

Freud, S. (1996h). Os três ensaios sobre a teoria da sexualidade. In Edição standard brasileira das obras psicológicas completas de Sigmund Freud. (vol. 7, pp. 119-232). Rio de Janeiro: Imago. (Originalmente publicado em 1905)

Frignet, H. (2002). O transexualismo. Rio de Janeiro: Companhia de Freud.

Lacan, J. (1998a). A instância da letra no inconsciente ou a razão desde Freud (1957-1958). In J. Lacan, Escritos (pp. 497536). Rio de Janeiro: Zahar.

Lacan, J. (1998b). A significação do falo. In J. Lacan, Escritos (pp. 692-703). Rio de Janeiro: Zahar.

Lacan, J. (1998c). De uma questão preliminar a todo tratamento possível da psicose. In J. Lacan, Escritos (pp. 537-590). Rio de janeiro: Zahar.

Lacan, J. (1998d). A agressividade em psicanálise. In J. Lacan, Escritos (pp.104-126). Rio de Janeiro: Zahar.

Lacan, J. (1999). O seminário, livro 5 - As formações do inconsciente (1957-1958). Rio de Janeiro: Zahar.

Lacan, J. (2002). O lugar da psicanálise na medicina (1966). Opção lacaniana, 32, 8-14.

Lacan, J. (2005). O simbólico, o imaginário e o real. In J. Lacan, Nomes-do-pai (pp. 9-55). Rio de Janeiro: Zahar.

Lacan, J. (2008a). O seminário, livro 7-A ética da psicanálise (1959-1960). Rio de Janeiro: Zahar.

Lacan, J. (2008b) O seminário, livro 20 - Mais, ainda (1972-1973). Rio de Janeiro: Jorge Zahar.

Lacan, J. (2009) O seminário, livro 18 - de um discurso que não fosse semblante (1971). Rio de Janeiro: Jorge Zahar.

Lacan, J. (2012). O seminário, livro 19 - Ou pior (1971-1972). Rio de Janeiro: Jorge Zahar.

Lacan, J. (s.d.). O seminário, livro 22 - R.S.I. (174-175). (Seminário não-publicado, edição bilíngue não oficial, sem data). 
Millot, C. (1992). Extrasexo: Ensaio sobre o transexualismo. São Paulo: Escuta.

Organização Mundial da Saúde [OMS] (1997). CID-10. Classificação internacional das doenças e problemas relacionados a saúde. 10a ed. São Paulo: Universidade de São Paulo.

Rinaldi, D. (2011). O corpo estranho. Revista latinoamericana de psicopatologia fundamental, 14(3), 440-451.

Stoller, R. (1982). A experiência transexual. Rio de Janeiro: Imago.

Von Krafft-Ebing, R. (2001). Psicopathia sexualis: As histórias de casos. São Paulo: Martins Fontes.

\section{Como citar:}

Possari, M. Y., \& Rinaldi, D. L. (2020). Transexualidade e Diferença Sexual: O que a Clínica nos Ensina. Revista Subjetividades, 20(Esp 2. O Contemporâneo à Luz da Psicanálise), e8897. http://doi.org/10.5020/23590777.rs.v20iEsp2.e8897

\section{Endereço para correspondência}

Doris Luz Rinaldi

E-mail: doris_rinaldi@yahoo.com.br

Mayara Yamauti Possari

E-mail: mayarapossari@gmail.com 